\title{
LAS INDUSTRIAS CREATIVAS DENTRO DEL DESARROLLO DE LAS CIUDADES Perspectivas y estrategias desde un enfoque económico, social y urbano
}

\author{
Copaja Alegre, Mónica \& Esponda Alva, Carlos \\ Universidad de Lima, Lima. Perú. \\ mcopaja@ulima.edu.pe,cesponda@ulima.edu.pe
}

\section{RESUMEN}

El proceso de crecimiento urbano trae consigo nuevas perspectivas en el desarrollo económico de las ciudades debido al surgimiento de nuevos mercados de producción que van reemplazando una industria de bienes hacia una de servicios. La aparición de la clase creativa marca el inicio para el desarrollo de una sociedad del conocimiento, teniendo al capital humano como principal motor del crecimiento económico y gestor de nuevas actividades de producción que operan desde las economías creativas. El presente estudio inicialmente delimita un marco conceptual de lo que significa el posicionamiento de las Industrias Culturales y Creativas para luego establecer un modelo que refleje una propuesta de análisis espacial en la ciudad de Lima donde se clasificará las diferentes actividades del sector creativo pudiendo construir una serie de indicadores que permitirán medir el impacto de las Industrias Creativas como estrategias para la mejora de la economía local y el desarrollo urbano.

Palabras claves: industrias culturales, industrias creativas, economía creativa, clase creativa

\begin{abstract}
The process of urban growth brings new perspectives in the economic field of cities due to the appearance of new industries that are replacing an industry of goods towards a service. The evolution of the creative class defines the beginning for the development of a knowledge society, with human capital as the main engine of economic growth and manager of new production activities that operate from the creative economies. The present study initially delimits a conceptual framework of what is meant by the positioning of the Cultural and Creative Industries to then establish a model that reflects a proposal of spatial analysis in the city of Lima where the different activities of the creative sector will be classified, being able to construct a series Of indicators that will allow to measure the impact of the Creative Industries as strategies for the improvement of the local economy and urban development.
\end{abstract}

Key words: cultural industries, creative industries, creative economy, creative class 


\section{INTRODUCCIÓN}

La aceleración del proceso de urbanización en el mundo ha motivado a una redefinición de los criterios de configuración de los centros urbanos. Actualmente, estos no solo representan sociedades posicionadas a través del tiempo, sino que involucran migraciones e influencias en su sector cultural, económico y social, donde el modo de vida de los ciudadanos traspasa la identidad de ciudad, prefiriendo optar por referencias y modelos externos que respondan a una sociedad globalizada.

En este contexto, los gobiernos se pueden favorecer de este fenómeno global como una oportunidad para reorientar sus ciudades hacia un enfoque sostenible según las potencialidades y necesidades de cada territorio. Para lo cual es necesario situar al ser humano como actor principal en este proceso, entendiéndolo como un ente provisto de talento, inteligencia, identidad y, sobre todo, con la capacidad de ser el gestor de una sociedad inclusiva; dejando atrás los procesos que nos definen como una sociedad consumista que emplea recursos no renovables como materia prima y economías de mercado excluyentes.

Este modelo de ciudad implica la revalorización de la cultura, entendida como un medio de comunicación que contextualiza los aspectos sociales, económicos y medioambientales. Sin embargo, la cultura como modo de vida se debe complementar de forma tangible con factores competitivos que involucren a la sociedad del conocimiento a partir de acciones que identifiquen y resalten a los sectores comprendidos en el ámbito cultural y creativo. Esto permitirá formular estrategias aplicadas al tejido económico, social y urbano de cada territorio, en función del capital humano y su estructura institucional como medios para promover una economía creativa, cuyo impacto podrá ser cuantificable dentro de una cadena de valor más humana y sostenible.

\subsection{Industrias Culturales y Creativas}

El término Industrias Culturales aparece en los años cuarenta, Adorno y Horkheimer (1944) en su obra "Dialéctica del lluminismo" las definen como la industrialización de la cultura, entendida como la transformación de una obra de arte hacia un sistema productivo de bienes y servicios con fines comerciales. La cultura siempre se desarrolló dentro de un ámbito aislado, perteneciente a un mercado elitista y excluyente. Sin embargo, desde la perspectiva de la sociología y la antropología, la cultura es un medio que define una sociedad para idear nuevos procesos sociales de desarrollo que favorezcan la consolidación de una identidad histórica, patrimonial y cultural. El resultado de esta paradoja propone la necesidad de generar una industria que resalte los valores culturales propios de la sociedad a través de procesos productivos, favoreciendo así, la exportación de recursos que contribuyan a la economía y al posicionamiento de cada sociedad en el mundo.

Posteriormente, se inician diferentes debates sobre el entendimiento de las Industrias Culturales partiendo de la necesidad de llegar a una definición coherente y homogénea. Una de las primeras organizaciones en presentar un modelo que respondiera a la sociedad de consumo de ese entonces, fue la Organización de las Naciones Unidas para la Educación, la Ciencia y la Cultura (UNESCO, por sus siglas en inglés) en 1986, donde reconocía e identificaba a los sectores comprendidos únicamente en el ámbito cultural, los cuales permitirían aportar a la economía de cada país en un mercado emergente. En 1997, Gran Bretaña a través de su Department of Culture, Media and Sports (DCMS), acuñó el término de Industrias Creativas, que complementariamente a las Industrias Culturales buscaban promover un desarrollo económico y social desde la explotación intelectual. Bajo esta nueva metodología, se clasificó el sector cultural y creativo en trece subsectores: publicidad, arquitectura, arte y antigüedades, artesanías, diseño, moda, cine y video, software de entretenimiento, música, artes escénicas, publicaciones, software y radio-televisión. Sobre estas bases, la Unión Europea (UE) empieza a poner en práctica estas estrategias identificando sus sectores culturales y creativos, y midiendo el efecto que tenían en el crecimiento económico, tanto por la cantidad de empleos generados, como por su aporte a la producción.

Sin embargo, las metodologías de estos organismos muchas veces no eran compatibles con las perspectivas de los países interesados en ejecutar políticas de fomento de las Industrias Culturales y Creativas (ICC), debido a que la delimitación de cada sector era imprecisa y las estrategias presentadas no eran viables para los mercados, alcances y realidades de cada uno de los países involucrados. A esto se suma el poco entendimiento respecto a la clase creativa - cuyo significado es el posicionamiento de una economía creativa en la sociedad (Florida, 2010) - que comienza a aparecer en una nueva sociedad del conocimiento, donde la creatividad ya no es solamente la capacidad de crear algo nuevo, sino también la oportunidad de darle un valor económico a todo el proceso creativo, integrando variables de innovación, tecnología, ciencia, arte y cultura. En este contexto, el sector cultural se redefine en función de las industrias creativas y en el 2010 la UNESCO, como principal representante de cultura a nivel global, presenta la "Guía para el desarrollo de las 
industrias culturales y creativas", que permite desarrollar estrategias a través de indicadores culturales y creativos para que los países puedan medir los alcances de las ICC en relación a la creación, producción y comercialización de contenidos creativos que sean intangibles y de naturaleza cultural (UNESCO, 2010).

Actualmente muchos países están implementando políticas públicas para repotenciar sus economías culturales y creativas, tomando como referencia la metodología presentada por la UNESCO sumada a otros sistemas de información estadística, como las Cuentas Satélite de Cultura. Estas permiten medir el impacto económico de los diversos sectores de las ICC, considerando principalmente el porcentaje de ingresos relacionado al Producto Bruto Interno (PBI) y la tasa de empleo que generan. Estos indicadores pueden ser equívocos (ver cuadro 1), pues no siempre expresan la verdadera cadena de valor correspondiente a las ICC. En ella intervienen diversos factores como la cantidad de exportaciones e importaciones de cada país para determinar si es productor de cultura y creatividad o si importa bienes y servicios de otros países.

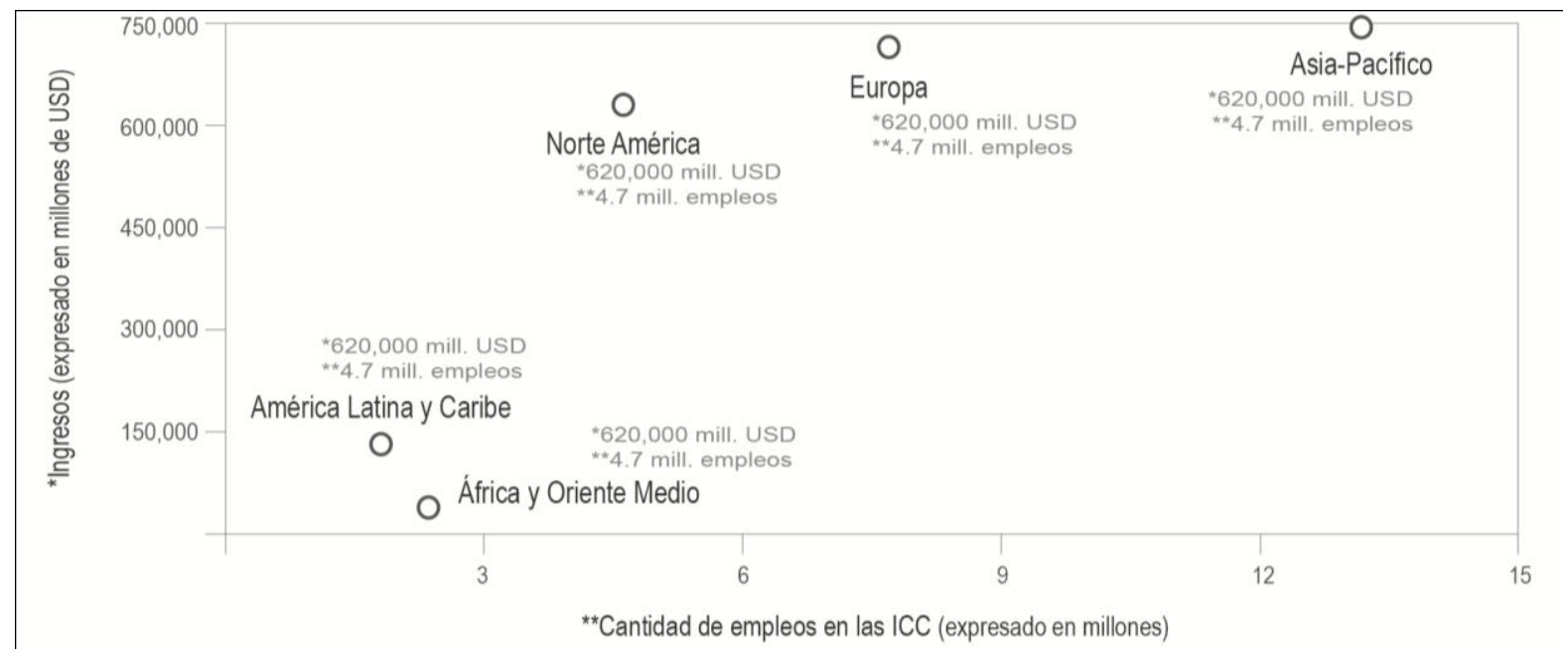

Tabla 1: Ingresos que aportan las Industrias Culturales y Creativas y la cantidad de empleos generados a nivel mundial Elaboración propia a partir de datos del primer mapa mundial de las industrias culturales y creativas (EY, 2015).

\subsection{La Economía Creativa}

El concepto de economía creativa es el resultado del proceso productivo que involucra a las ICC. Su significado aún continúa redefiniéndose debido a los cambios socio-económicos en el escenario internacional, donde se ha ido consolidando la sociedad del conocimiento y la información como actor principal de este crecimiento económico. Lo cultural no es independiente a lo creativo, ya que cada persona cuando produce un bien o servicio desarrolla un sentido de creación. Sobre esta idea, todos podemos aportar dentro de esta cadena de valor cambiando los patrones de producción desde una visión integral que promueva la inclusión social, interdisciplinaria y participativa, apartándose de la visión elitista de la cultura como un privilegio.

El Banco Interamericano de Desarrollo (BID) en el Libro Naranja, define la economía creativa como "una riqueza enorme basada en el talento, la propiedad intelectual, la conectividad y por supuesto, la herencia cultural de nuestra región" (Restrepo y Márquez, 2013:10). Este manual explica las "oportunidades infinitas" que tienen los sectores creativos en América Latina para su posicionamiento, mostrando cifras e indicadores cuantitativos que reflejan un panorama favorable del sector creativo en la región. La economía naranja se categoriza en bienes creativos (artes visuales y performativas, artesanía, audiovisual, diseño, nuevos medios) y en servicios creativos (arquitectura, cultura y recreación, investigación y desarrollo y publicidad).

La vía para impulsar las economías creativas estará determinada por la capacidad de innovación y creatividad del capital humano y su sociedad, la cual puede ser adquirida y maximizada mediante políticas de educación que promuevan el emprendimiento a través de I+D+i (investigación, desarrollo e innovación). El intelecto de cada individuo, entendido como materia prima inagotable, debe ampararse en los derechos de autor y del copyright, por lo que la Organización Mundial de la Propiedad Intelectual (OMPI) viene desarrollando una metodología que contribuirá con este factor. Adicionalmente, disponer de nuevas Tecnologías de la Información y Comunicación (TIC), como medios de difusión y atracción de nuevos actores y mercados, puede generar un nuevo entendimiento en la estructura de las economías creativas, eliminando el espacio real y ampliando la cobertura en la cadena de valor de las ICC. Por otro lado, es necesario fomentar la creación de clústeres y organizaciones que ejecuten proyectos innovadores respaldados por organizaciones del tipo startups, incentivando el crecimiento competitivo que se viene desarrollando en el ecosistema creativo. 


\subsection{Lógicas espaciales y el factor territorial}

El surgimiento y fomento del sector creativo supone una reconfiguración del sistema social, económico y urbano actual de las ciudades que optan por el modelo de economía creativa. La creatividad como recurso ilimitado (propio del intelecto de las personas), conlleva a cuestiones sobre cómo adecuar y condicionar el territorio, para lo cual se debe conocer las interrelaciones que tiene esta clase creativa aún poco estudiada. El desinterés tanto de los gobiernos y sectores públicos, como de los economistas y sectores privados (asociados a las industrias culturales), ha generado que este sector emergente se vea obligado a trabajar formando medianas, pequeñas y sobre todo micro empresas disgregadas y muchas veces informales, lo que dificulta reconocer su geografía económica dentro del suelo urbano.

Dentro de las estrategias de impulso a las Industrias Creativas, se resalta el método de mapeo que permite localizar a la clase creativa, identificar el tipo de suelo y contexto donde se desarrolla, así como su interrelación con los demás sectores de la economía local. Es importante reconocer a este sector emergente dentro de un ámbito multi-institucional, que trabaja con y para diversas áreas ya consolidadas en el territorio. Lo cual plantea un cuestionamiento sobre la reestructuración de los núcleos de desarrollo para consolidar físicamente a este sector sobre el tejido social y urbano, o de otro modo, consolidarlo dentro de un espacio digital propio de esta sociedad de la información, donde las tecnologías facilitan nuevos modos de trabajo modificando los paradigmas en la cadena de valor de este sector económico.

Ahora bien, tratándose de un mercado industrial, es necesaria su aparición dentro del territorio. Florida (2002) expone que la creatividad se da en un inicio en la mente e idealismo de cada persona, sin embargo su materialización se da en condiciones de trabajo colectivo, resultando en productos y servicios novedosos y útiles. Complementariamente, desde el ámbito de la cultura y de las industrias culturales, sobresalen las experiencias de Barcelona y Medellín, las cuales a través de una acupuntura urbana con infraestructuras culturales, establecen polos y ejes culturales que atraen mercados de consumo, oportunidades de producción y turismo. Bajo este entendimiento, se debe posicionar núcleos creativos dentro de la ciudad que generen el mismo efecto positivo, pero desde una perspectiva —en conjunto a la cultural— que estimule el emprendimiento, la innovación y la tecnología (como es el caso de Silicon Valley), y determine mercados para ofrecer productos comercializables, fomentando la competitividad de las empresas en este rubro. La concentración del sector creativo resulta de una gestión de políticas que apoyen y faciliten la formación de clústeres como puntos estratégicos en la ciudad "que proporcionen un ecosistema amplio que nutra y fomente la creatividad" (Florida, 2010:23). Estos viabilizan una reinvención de barrios, como es el caso de Buenos Aires, que a través de sus distritos temáticos potencializa las características propias de cada uno de ellos, atrayendo a nuevos consumidores y aportando en la economía del territorio.

\section{PANORAMA DE LAS INDUSTRIAS CULTURALES Y CREATIVAS}

\subsection{Políticas públicas en Europa y América Latina}

La situación actual del sector creativo en Europa está encaminada bajo un legado cultural muy marcado por la tradición y la riqueza de su patrimonio histórico y las actividades que este engloba, sociológica y económicamente. El estudio de Tiempos de Cultura (EY, 2015) describe que "la fuerza de las Industrias Culturales y Creativas europeas (ICC) es la concentración única de instituciones patrimoniales y artísticas con una historia antigua, rica y diversificada. 7 de los 10 museos más visitados del mundo están en Europa y 30 de las 69 ciudades creativas de la UNESCO son europeas". La consolidación de la Unión Europea trajo ventajas para el fomento de las ICC, pues permitió abordar líneas de trabajo dentro de políticas comunes entre los estados miembros, teniendo como objetivo común impulsar el sector cultural y creativo en beneficio de la potenciación de su tejido económico y social. Bajo un proceso de interculturalidad, se desarrollan métodos de cooperación benéfica entre los estados, compartiendo experiencias válidas e inválidas a través de intercambios culturales para redefinir las políticas públicas. No obstante, desde una perspectiva antropológica y social, el concepto de cultura como generatriz del sector creativo hacia su propia industrialización, generó discusiones sobre los riesgos de una pérdida y sustitución de la esencia de la cultura, pues limitaba su significado a un aspecto económico. En un escenario donde predomina la sociedad de consumo y donde poco a poco la economía de la cultura —entendida desde la definición de Industrias Culturales y la cadena de valor que trae consigo, así como desde los ámbitos culturales tradicionales como patrimonio y arte - va perdiendo demanda, lo cual se refleja en la disminución de su tasa de crecimiento. Por otro lado, el sector creativo genera mayor valor económico frente al cultural, pues abarca conceptos de 
innovación, producción tecnológica y servicios más acordes a las necesidades sociales contemporáneas de consumo, ofertadas por las economías del conocimiento.

Esto significó un gran reto para Europa en el diseño de un modelo de desarrollo que reconfigure su mercado y patrimonio cultural según las demandas de una sociedad de consumo creativa e innovadora. Por un lado, se elaboró el Libro Verde que buscó impulsar el sector audiovisual en su transición hacia la era digital, motivando políticas de apoyo y promoción de la televisión y el cine europeo. Por otro lado, los estados y ciudades de la UE iniciaron proyectos de desarrollo aplicados en las ICC para acondicionar el tejido urbano en favor del fomento y disposición espacial de la clase creativa. Para ello se trabajaron políticas territoriales y culturales, sumadas a procesos de gentrificación urbana - vista desde un cambio social en el territorioque facilitaron la configuración de infraestructuras y núcleos culturales, como es el caso de las Olimpiadas de Barcelona de 1992 y el Fórum Universal de las Culturas en el 2004. Asimismo, el proyecto "22@Barcelona" constituye un distrito innovador por la aglomeración espacial de industrias creativas y del conocimiento, donde se ofertan productos y servicios de un mercado de emprendedores a través de la I+D+i, la ciencia y la tecnología. Como proyección de los Juegos Olímpicos del 2024, "París 2024" se presenta como un proyecto alineado a la Agenda 21, promoviendo la innovación, la cultura y el patrimonio, bajo criterios de una ciudad sostenible que rehabilita sitios en desuso, lo que le permite a la ciudad seguir reinventándose. Además es importante reconocer que Europa se define por una interculturalidad promovida por los altos flujos migratorios en el territorio (debido a los vuelos de bajo costo y las fronteras abiertas), lo cual es positivo para el turismo y la atracción de la clase creativa. Esto implica que cada región defina una imagen o marca de ciudad para atraer y consolidar mercados creativos y economías del conocimiento, cuyas sinergias promoverán un desarrollo económico, cultural, industrial y sostenible en el territorio. De este modo, Europa se podrá posicionar como potencia económica competitiva frente a otros mercados mundiales.

América Latina ha comenzado a adoptar políticas públicas que promueven las ICC y apuntan a la cultura como pilar de desarrollo. Sin embargo, el impacto que generan en su economía no representa un potencial relevante frente a otros sectores económicos. El informe de Tiempos de Cultura (EY, 2015) señala que el aporte de las ICC en América Latina representa solo el $6 \%$ de ingresos a nivel mundial, comparándolo con Asia que se posiciona con un 33\%. Cabe destacar que en los últimos años muchos de los países latinoamericanos han generado un crecimiento representativo reflejado por indicadores de exportaciones culturales (sector audiovisual y editorial) que evidencia una mayor contribución del sector cultural y creativo a la economía local; no obstante, los países centroamericanos todavía experimentan dificultades para generar mecanismos de medición y diagnóstico de la estructura cultural en su tejido económico. Por otra parte, la sociedad latinoamericana se visualiza como importadora de cultura y creatividad de consumo, principalmente de los Estados Unidos, líder en el sector tecnológico y digital. A pesar de que la mayoría de países de la región incluyen cláusulas de "Excepción Cultural" en sus Tratados de Libre Comercio (TLC), las estadísticas reflejan la insuficiente participación de las cadenas productivas de bienes y servicios culturales en el crecimiento económico. Esto significa un riesgo en la consolidación de una imagen e identidad en la región, acentuando una pérdida de valores que desarticula cualquier tipo de cohesión social.

La UNESCO ha elaborado metodologías de clasificación de los indicadores culturales que fomentan el desarrollo de las ICC. Estas herramientas ofrecen a los países latinoamericanos reconocer, a través de datos cuantitativos, las cadenas de valor que representa el sector cultural de cada país en beneficio de su desarrollo hacia la ejecución de políticas públicas coherentes. Asimismo, el Banco Interamericano de Desarrollo (BID) dispone de proyectos para la difusión de los productos culturales y creativos; así, por ejemplo, "La Economía Naranja" busca destacar la importancia de la economía creativa desde el talento, la creatividad y la tecnología, tomando como base la herencia cultural de la región. Estas herramientas se ven limitadas por la falta de implementación de acciones y programas gubernamentales que reconozcan los nichos específicos de sus economías culturales y creativas, consecuencia de la carencia de datos recogidos en torno a las ICC. En el 2009, el BID, junto a la Agencia Española para la Cooperación Internacional al Desarrollo (AECID) y la Organización del Convenio Andrés Bello, presentaron la guía "Cuentas Satélites de Cultura, el Manual metodológico para su implementación en Latinoamérica", que por medio de mecanismos de medición e indicadores estadísticos, permite visibilizar y valorar las actividades y productos culturales desde su contribución al crecimiento económico del país. Esta metodología ya ha sido aplicada por Argentina, Brasil, Colombia, Chile, Costa Rica, México y Uruguay para ampliar sus líneas de trabajo respecto a las ICC. La alianza estratégica de los países que integran el MERCOSUR, a través del Sistema de Información Cultural, facilita la obtención de datos con el objetivo de registrar en mapas culturales la diversidad de estos sectores. Esto impulsa a los estados hacia una línea de intervención que identifique a los actores del sector cultural y creativo (reconocimiento de las pequeñas y medianas empresas, incluso las informales que son muy evidentes en la economía latinoamericana) para la gestión de políticas públicas en beneficio del capital 
humano como fuente de motor económico, y de la propiedad intelectual como respaldo y motivación para el desarrollo de actividades creativas.

A finales del siglo XX surgen iniciativas de intervención sobre el suelo urbano que responden a las problemáticas de la sociedad latinoamericana; sin embargo, la baja visibilidad del sector cultural y la poca confianza que le tenían los gobiernos como sector económico posible, promueven una ciudad fragmentada sin un rumbo en el desarrollo social y sostenible, donde la calidad de vida está limitada a sectores sociales y económicos dispersos. Los usos y costumbres de las sociedades quedaron minimizados a un entendimiento básico cultural desde la tradición e identidad "histórica" propia de cada una de ellas y no consideraba sus potencialidades desde una visión de cohesión social como punto de partida para un desarrollo urbano. A partir de la inserción del concepto de las ICC, muchas ciudades latinoamericanas crearon estrategias de acupuntura urbana revitalizando distintos sectores olvidados de las ciudades, incluso en zonas periféricas donde el valor del suelo sugería que aquellos sectores no representaban una oportunidad de intervención. En el caso de Puerto Madero en Buenos Aires, se recuperó la zona portuaria industrial próxima al centro histórico de la ciudad, y se estableció como un eje de espacio público que impulsó el desarrollo de usos residenciales y comerciales, así como empresas, inversiones y turismo. Asimismo, se emprendió el proyecto de barrios temáticos para potenciar su identidad, como son Palermo y San Telmo. De igual manera, Colombia implementó políticas para posicionar sus ciudades dentro de un contexto cultural y de innovación internacional. En el caso de Bogotá, el Plan Maestro de Equipamientos Culturales promovió el acceso a la cultura por medio de la construcción de infraestructuras culturales en distintas zonas de la ciudad, generando corredores culturales para una renovación urbana en base a la economía cultural. La propuesta de recontextualización de Medellín a través de un urbanismo social, la ubica entre las principales ciudades innovadoras, recibiendo el premio Lee Kuan Yew World City Prize en el 2016. La Ruta N y el proyecto Medellinnovation se constituyen como estrategias para establecer clústeres de sectores creativos y emprendedores, que fomenten la innovación e inclusión a través de la economía del conocimiento.

\subsection{Aproximaciones y ejes de acción}

En el panorama actual, las Industrias Culturales y Creativas se presentan como modelos de desarrollo necesarios dentro de mercados económicos competitivos. La evidencia de su aporte en el crecimiento económico, traducido en las tasas de empleo y su contribución en el PBI, confirman que no se trata de un mercado emergente, sino de uno de los principales sectores de producción de bienes y servicios que engloban mercados culturales, creativos, innovadores, sociales, sostenibles y tecnológicos. Desde el campo urbano y de desarrollo de nuevas posturas sociales, las ICC permiten fomentar un modelo de ciudad inteligente, que se caracteriza por emplear las TIC para afrontar los desafíos de una ciudad convencional, y apunta hacia un desarrollo competitivo y sostenible por medio de la participación del "ciudadano inteligente" en la toma de decisiones y la planificación colectiva de la ciudad.

Las políticas de gestión no deben generalizar las capacidades particulares de un territorio a nivel de estado. Por ejemplo, las Comunidades Autónomas Españolas idearon programas públicos enfocados únicamente en promover sus industrias audiovisuales dentro de un marco global, cuando en la práctica no todas las comunidades destacaban por ese contenido (Zallo, 2009). Por ello la necesidad de trabajar con las Cuentas Satélites de Cultura, sobre todo en Latinoamérica, para identificar los sectores culturales y creativos que sobresalen y son coherentes con la identidad de su región. Esto permitirá que el capital humano disponible se identifique con la cadena de valor a emprender y pueda fortalecer los vínculos sociales del territorio. La agenda pendiente de los estados y ciudades frente al posicionamiento de las ICC deja abierto el debate sobre las diferentes medidas y posturas que cada uno de ellos debe adoptar. Sin embargo, el presente artículo considera aspectos específicos según el caso de estudio presentado, inmerso en la región latinoamericana, esbozando las siguientes consideraciones para el fomento de las Industrias Culturales y Creativas:

- Desde un marco de planeación y gobernanza. Cada territorio debe idear un modelo de ciudad coherente que le permita establecer una gestión de políticas públicas (con una visión de corto y largo plazo), que considere los principales sectores característicos de sus ICC a partir de metodologías y manuales presentados por los diversos organizamos internacionales, siendo competencia propia definir y trabajar en sus propios indicadores de desarrollo.

- Desde el factor económico del sector cultural y creativo. Es necesario medir el impacto y la contribución de la promoción de las ICC por medio de Observatorios de Cultura y Economía y de una Cuenta Satélite de Cultura que facilite un sistema de obtención de datos para medir el crecimiento económico que genera el sector cultural y creativo - determinado por la producción de los bienes y servicios, su oferta y demanda, y la tasa de empleo- considerando a pequeñas, medianas y grandes empresas. 
- Desde un marco espacial en el territorio. Las iniciativas de gentrificación y renovación urbana favorecen la inserción de infraestructuras de carácter cultural y de servicios públicos que promuevan el desarrollo de actividades de las industrias culturales, dinamizando diversos sectores del territorio principalmente en la periferia (si se trata de una ciudad fragmentada). La sectorización de corredores y clústeres culturales permitirán a través de la economía de la cultura y plusvalías aportar al desarrollo económico, promoviendo una competitividad que oferte un mercado cultural y creativo consolidado.

- Desde el marco del capital humano como capacidad emprendedora. Se debe alinear el talento creativo e innovador a las oportunidades de aportar a través de la $I+D+i$, a los diferentes sectores económicos del territorio, y no solo al cultural y creativo. Para ello se debe planificar desde una recontextualización del tejido urbano y social en el que la clase creativa pueda insertarse, brindándole facilidades para su fomento.

- Desde el factor de cohesión social a través de Imaginarios Urbanos. El modo cómo una sociedad percibe su ciudad es fundamental, pues la apropiación del territorio por sus ciudadanos denota el impulso que necesitan las ciudades actuales. El progreso social y económico de una sociedad no siempre se debe a su modo de gobernanza y sus políticas públicas, sino también al índice de felicidad y bienestar en los ciudadanos, quienes bajo el derecho de una participación ciudadana en la formulación del territorio, eligen qué modelo de ciudad desean, según el patrimonio, costumbres e identidad de cada región.

\section{ESTADO Y PERSPECTIVAS ECONÓMICAS}

\subsection{Contexto económico global y regional}

La economía mundial ha sufrido grandes cambios en los últimos años, desde la salida de Reino Unido de la Unión Europea hasta las actuales decisiones de los Estados Unidos respecto al comercio, la migración y la tecnología. A pesar de ello, la demanda de productos aumentó beneficiando los mercados latinoamericanos y el crecimiento en países como México, Perú, Ecuador y Colombia. Asimismo, Argentina y Brasil proyectan una variación positiva de $2,2 \%$ y $0,2 \%$ en su PBI respectivamente (ver cuadro 2 ). Estos cambios trascienden en la economía peruana, la cual se mantiene estable ante el mercado global, disponiendo de recursos y de un ritmo constante de producción. Bajo el enfoque de apertura de nuevos sectores económicos, es necesario formular estrategias hacia un modelo de desarrollo basado en el capital intelectual como principal recurso, el cual ya ha sido implementado en diversos países y representó en el 2005 el 6,1\% de la economía global, alcanzando los 4,3 billones de dólares para el 2011, además según la Conferencia de las Naciones Unidas para el Comercio y el Desarrollo (UNCTAD), las exportaciones de bienes y servicios creativos crecieron 134\%, alcanzando la suma de 646 mil millones de dólares (Duque Márquez y Buitrago Restrepo, 2013).

\begin{tabular}{cccccccc}
\hline año & Argentina & Brasil & Colombia & Chile & México & Perú & Venezuela \\
\hline 2015 & 2.5 & -3.8 & 2.5 & 3.1 & 2.6 & 3.3 & -6.2 \\
2016 & -2.4 & -3.5 & 1.6 & 1.9 & 2.2 & 4.0 & -12.0 \\
2017 & 2.2 & 0.2 & 2.1 & 2.6 & 1.7 & 4.3 & -6.0 \\
2018 & 2.8 & 1.5 & 2.7 & 3.5 & 2.0 & 3.5 & -3.0 \\
\hline
\end{tabular}

Tabla 2: Variación porcentual del PBI en América Latina por año.

Elaboración propia a partir del informe Perspectivas de la economía mundial (informe WEO) (FMI, 2016).

Actualmente el Perú se encuentra en una situación favorable, según el INEI (2016), en el tercer trimestre del 2016, el PBI registró un crecimiento de 4,4\%, así como en la demanda externa con 16,7\%. Asimismo, según el Ministerio de Trabajo y Producción de Empleo (2015), de la población económicamente activa, el 96,5\% son parte de la PEA ocupada, de la cual $39,0 \%$ está vinculada al sector servicios, el $26,9 \%$ está enfocado a actividades extractivas, el $18,2 \%$ al comercio, el $9,4 \%$ a la industria y el $6,6 \%$ a la construcción. Por otro lado, según los Indicadores Unesco de Cultura para el Desarrollo (UNESCO, 2014) se puede observar que las actividades culturales han contribuido en el crecimiento del PBI en 1.58\% tomando el 2007 como año base según el INEI, siendo el $26 \%$ actividades centrales y el $74 \%$ actividades de apoyo. Sin embargo, solo están contabilizadas las actividades formales y privadas dejando de lado las actividades realizadas por instituciones públicas o sin fines de lucro. A pesar de ello, la contribución del ámbito cultural al PBI es sumamente significativa al compararlo con otras industrias con contribuciones como el $0,9 \%$, el $0,7 \%$ o el $1,7 \%$ como las de muebles y madera, pesca y agricultura o actividades concernientes a electricidad, gas y agua.

Analizando el sector económico cultural y creativo en el Perú (cuya caracterización dentro de las estadísticas y sistemas de información no figura claramente, o la disponibilidad de datos no es favorable), se percibe que el 3,3\% de la población ocupada en el Perú estaba vinculada con actividades culturales en el año 2007, el 
$90 \%$ de ellas estaba involucrada en actividades centrales, mientras que el $10 \%$ restante cumplían actividades de apoyo, observándose que las actividades ligadas a la creatividad y cultura fueron el $4,36 \%$ del empleo total en el 2007 (UNESCO,2014). Sin embargo, según el informe de Producción y Empleo Informal en el Perú (INEI, 2015a), de la población ocupada, el 73\% pertenece al sector informal, siendo esta la quinta parte del PBI del Perú y, a pesar de haberse reducido en el último año, supera a Chile, México y en algunos casos a Colombia. Esto ocurre debido al costo que conlleva tener un negocio formal o ser contratado formalmente contrarrestado con los beneficios, por lo tanto, se necesitan nuevas políticas públicas para incrementar la dinámica laboral formal y nuevos modelos que brinden mayores beneficios ya que el índice de la PEA crece sin contar con un sistema lo suficientemente efectivo para satisfacer adecuadamente a la demanda laboral.

\begin{tabular}{lcccc}
\hline & 2007 & 2009 & 2013 & 2015 \\
\hline PBI (millones de soles) & 319,693 & 352,693 & 456,435 & 482,370 \\
\hline variación porcentual \% & 8.5 & 1.1 & 5.9 & 4.2 \\
\hline Extractivo & 67,309 & 73,015 & 80,646 & 85,527 \\
Transformación & 69,124 & 73,919 & 99,383 & 96,225 \\
Servicios & 183,239 & 205,759 & 276,406 & 300,618 \\
\hline * Sector Cultural & 5,051 & 9,522 & - & - \\
\hline PEA (miles de personas) & $14,903.3$ & $14,757.7$ & $15,683.6$ & $15,918.9$ \\
\hline Extractivo & - & $4,115.4$ & $4,047.9$ & $4,282.8$ \\
Transformación & - & $1,604.5$ & $1,590.2$ & $1,501.8$ \\
Servicios & - & $9,037.8$ & $10,176.7$ & $10,134.4$ \\
\hline * Sector Cultural & 491.8 & - & - & - \\
\hline
\end{tabular}

* el sector Cultural está incluido dentro del sector Servicios.

Tabla 3: PERÚ: PBI (millones de soles) y PEA (miles de personas) por año y sector económico.

Elaboración propia a partir de datos estadísticos presentados en Población económicamente activa según ámbito geográfico, $2004-2015$ (INEI, 2015b) y PERU: Producto Bruto Interno por años según actividades económicas por el (INEI, 2015c), El ítem cultural se calculó a partir de la información obtenida de los Indicadores UNESCO de Cultura para el Desarrollo (UNESCO, 2015).

A la fecha, el Estado ha comenzado a tomar iniciativas para impulsar el desarrollo de las ICC, siendo una posible forma de enfocar la oferta laboral y contrarrestar la informalidad en el Perú. El Ministerio de la Producción inauguró una Mesa Ejecutiva de Industrias Creativas en Mayo del 2015 para promover diversos sectores culturales. Asimismo, según el Centro Nacional de Planeamiento estratégico (CEPLAN), las ICC en el Perú podrían generar entre 10,000 y 15,000 millones de dólares para el 2021. Además, en el 2012 el Ministerio de Cultura presentó el "Atlas de Infraestructura y Patrimonio Cultural de las Américas" impulsado por el BID, recopilando información estadística sobre la diversidad del patrimonio cultural y la infraestructura cultural en el Perú.

\begin{tabular}{lcc|cc}
\hline & $\begin{array}{c}\text { Aporte del sector } \\
\text { cultural al PBI }\end{array}$ & $\begin{array}{c}\text { Empleo ocupados en } \\
\text { el sector cultural }\end{array}$ \\
\hline Argentina & $\%$ & $\begin{array}{c}\text { año de la } \\
\text { muestra }\end{array}$ & $\%$ & $\begin{array}{c}\text { año de la } \\
\text { muestra }\end{array}$ \\
\hline Brasil & 3 & 2015 & 2.5 & 2014 \\
Chile & 2.7 & 2011 & 1.3 & 2012 \\
Colombia & 1.58 & 2010 & 1.3 & 2011 \\
Costa Rica & 3.41 & 2014 & 2.1 & 2014 \\
Ecuador & 0.4 & 2015 & 0.42 & 2015 \\
México & 0.98 & 2009 & 0.8 & 2011 \\
Perú & 2.8 & 2014 & 1.98 & 2014 \\
Paraguay & 2.7 & 2009 & 1 & 2011 \\
República Dominicana & 3.9 & 2011 & 1 & 2010 \\
Uruguay & 1.5 & 2014 & 4.4 & 2014 \\
Venezuela & 1.89 & 2008 & 2.6 & 2011 \\
\hline & 1.58 & 2003 & 0.33 & 2000 \\
\hline
\end{tabular}

Tabla 4: Aporte del sector cultural al PBI y a la tasa de empleos en países de América Latina 
Elaboración propia a partir del informe del CEPAL (2014) para los países de Argentina, Brasil, Ecuador, Paraguay (se agrega datos del Banco Central de Paraguay), Perú, Uruguay y Venezuela (se agrega datos de la investigación de Guzmán, Medina y Aguilar, 2005). Para los países de Argentina, Costa Rica, México y República Dominicana se empleó datos de sus Cuentas Satélites de Cultura con el Convenio Andrés Bello. Para Chile se obtuvo información del Mapeo de Industrias Creativas en Chile. Para Colombia se utilizan datos del resumen analítico de los Indicadores UNESCO de Cultura para el Desarrollo - Colombia.

\subsection{Contexto económico en Lima}

La ciudad de Lima, que posee el mayor porcentaje del PBI nacional, ha tenido una variación promedio de $6,4 \%$ respecto a los años 2010 al 2015 y abarcó el 44,4\% del PBI nacional en el 2015. Por otro lado, también posee el mayor porcentaje de PEA del Perú la cual ha ido aumentando progresivamente desde el 2008 pasando de 4012,1 a 4756,9 (miles de personas) al 2016. Refiriéndonos a la población en edad de trabajar, el $68,9 \%$ de PET son parte de la PEA y de ese porcentaje el 93,1\% pertenece a la PEA ocupada. Según las ramas de actividad económica podemos visualizar que la PEA en Lima ha tenido una variación de $2,9 \%$ en el primer trimestre del 2016, porcentaje alentador a pesar del decrecimiento de ciertos sectores, tales como el comercio $(-4,5 \%)$, el sector construcción $(-1,5 \%)$; sin embargo, hubo un crecimiento en la manufactura $(2,8 \%)$ y en servicios (6,5\%) (Ministerio de Trabajo y Promoción del Empleo, 2015).

El mayor porcentaje de aporte de las actividades culturales al PBI nacional proviene de Lima debido al centralismo del país, sin embargo los datos son insuficientes para cuantificar este hecho. Por ejemplo, el $25 \%$ de los museos existentes en el Perú se encuentran en la capital, de los cuales el 18,8\% están administrados por entidades del estado, además, existen 64 centros culturales entre públicos y privados. Por otro lado según la encuesta realizada por Lima Cómo Vamos en el 2015, el Ministerio de Cultura organizó 718 actividades culturales en Lima, a través de la dirección de industrias creativas y arte, el Gran Teatro Nacional, la Dirección de participación ciudadana, entre otros. Asimismo, existen programas del estado como Cultura Viva y Vamos al Museo las cuales están a cargo de la Municipalidad Metropolitana de Lima (Lima Cómo Vamos, 2015).

\begin{tabular}{lcccc}
\hline & 2009 & 2013 & 2014 & 2015 \\
\hline PBI (miles de soles) & 148910,138 & 200400,691 & 207929,994 & 214243,677 \\
\hline variación porcentual \% & 0.3 & 5.7 & 3.8 & 3.0 \\
\hline Extractivo & 6126,661 & 7622,497 & 7878,072 & 8428,117 \\
Manufactura & 30577,640 & 41137,666 & 41097,464 & 40333,370 \\
Construcción & 9112,210 & 12761,679 & 12956,795 & 12146,871 \\
Comercio & 19483,244 & 26703,869 & 27210,513 & 28419,581 \\
Transportes y Comunicaciones & 16577,689 & 24314,080 & 25468,341 & 26880,112 \\
Servicios & 59974,728 & 87860,900 & 93318,809 & 98035,626 \\
\hline PEA (miles de personas) & $4,495.2$ & 4,891 & $4,869.5$ & $4,962.7$ \\
\hline Extractivo & 60.3 & 66.3 & 54.9 & 73.1 \\
Manufactura & 740.5 & 715 & 700.4 & 735.9 \\
Construcción & 738.2 & 350.4 & 354.2 & 405.9 \\
Comercio & 2,542 & 1,191 & $1,139.9$ & $1,054.3$ \\
Transportes y Comunicaciones & 448.5 & 497.7 & 496.8 & 549.4 \\
Servicios* & $2,036.1$ & $2,070.5$ & $2,132.2$ & $2,144.1$ \\
\hline
\end{tabular}

el sector Cultural está incluido dentro del sector Servicios.

Tabla 5: LIMA: PBI (miles de soles) y PEA (miles de personas) por año y sector económico.

Elaboración propia a partir de datos estadísticos presentados en Población económicamente activa según ámbito geográfico, 2004-2015 (INEI, 2015b) y Lima: Valor Agregado Bruto por Años, según Actividades Económicas por Años (INEI, 2015d).

\section{CASO DE ESTUDIO: LIMA}

El presente estudio tiene como objetivo conocer mejor las ICC de Lima a partir de la recolección y unificación de datos que sirvan de insumo para la medición de la oferta creativa actual. Adicionalmente, se ha analizado esta información para establecer un primer diagnóstico y formular lineamientos que favorezcan al fortalecimiento de las mismas. Dado que el sector creativo en Lima es amplio, diverso y se encuentra en constante actualización, esperamos también que esta investigación pueda contribuir como punto de partida en el desarrollo de una red de mapeo que concentre la información de las distintas iniciativas aisladas.

\subsection{Metodología de estudio}

\subsubsection{Delimitación del concepto de Industrias Culturales y Creativas}


Para el presente estudio, se tomará la definición de la UNESCO (2010:17) entendiendo las industrias culturales y creativas como: "aquellos sectores de actividad que tienen como objeto principal la creatividad, la producción o reproducción, la promoción, la difusión y la comercialización de bienes, servicios y actividades de contenido cultural, artístico o patrimonial".

Además se delimita el concepto de Industrias Culturales como: "aquellas industrias que combinan la creación, la producción y la comercialización de contenidos creativos que sean intangibles y de naturaleza cultural. Estos contenidos están normalmente protegidos por copyright y pueden tomar la forma de un bien o servicio. Las industrias culturales incluyen generalmente los sectores editorial, multimedia, audiovisual, fonográfico, producciones cinematográficas, artesanía y diseño" (UNESCO, 2006:2); y el de Industrias Creativas como "un conjunto más amplio de actividades que incluye a las industrias culturales más toda producción artística o cultural, ya sean espectáculos o bienes producidos individualmente. Las industrias creativas son aquellas en las que el producto o servicio contiene un elemento artístico o creativo substancial e incluye sectores como la arquitectura y publicidad" (Unesco, 2006: 2). Ambas definiciones serán el punto de partida para realizar una propuesta de caracterización de todas las actividades que competen al sector cultural y creativo en Lima.

\subsubsection{Agrupación de sectores creativos diversos}

En esta etapa se han agrupado los diversos sectores de ICC para facilitar el estudio. Para ello se han analizado diferentes categorizaciones tomando como referencia el Framework for Cultural Statistics (FCS) de la UNESCO (2009), el modelo del Department of Culture, Media and Sports de Reino Unido (2001), la guía expuesta en la Conferencia de las Naciones Unidas sobre Comercio y Desarrollo (con siglas en ingles UNCTAD) en el 2004, la teoría de círculos concéntricos de Thorsby (2007) y el Mapa de Industrias Creativas para Chile (2014). Las cuales han servido como punto de referencia para proponer una categorización que se aplique al ámbito local del caso de estudio.

Framework for Cultural Statics (FCS) - UNESCO. 1986.

Herencia cultural - impresión y literatura - música - artes de espectáculo - medios fonográficos - medios audiovisuales - actividades socioculturales - deportes y juegos - medio ambiente y naturaleza.

Department of Culture, Media and Sports (DCMS) - Reino Unido. 2001

Publicidad - arquitectura - artes y mercado de antigüedades - artesanías - diseño - diseño de moda - cine y video - softwares interactivos de entretenimiento - música - artes de actuación - edición - software y servicios de computación - televisión y radio.

Conferencia de las Naciones Unidas sobre Comercio y Desarrollo (UNCTAD). 2004

Herencia cultural: sitios culturales - sitios arqueológicos, museos, bibliotecas, exposiciones, etc. - expresiones culturales tradicionales - artes y oficios, festivales y colaboraciones.

Artes: artes escénicas - música en vivo, teatro, danza, ópera, circo, etc. - artes visuales - pintura, escultura, fotografia y antigüedades.

Medios: edición y medios impresos - libros, prensa y demás publicaciones - diseño - interiores, gráfico, moda, joyería y juguetería - audiovisuales - cine, televisión, radio, otras dimensiones - medios nuevos - programas de informática, juegos de consola, contenidos creativos digitalizados.

Creaciones funcionales: medios nuevos - arquitecturales, publicitarios, I+D creativos, culturales y recreativos.

Thorsby - Teoría de los Círculos Concéntricos de la Industria Creativa. 2007

Artes creativas centrales: literatura, música, artes escénicas, artes visuales.

Otras industrias culturales centrales: cine - museos, galerias, bibliotecas - fotografia.

Otros sectores productivos: publicidad - arquitectura - diseño - moda

Industrias culturales mas amplias: servicios del patrimonio - edición y medios impresos - televisión y radio - grabaciones de audio - videojuegos.

Mapeo de Industrias Creativas de Chile. 2014.

Artesanías - artes visuales - fotografía - teatro - danza - artes circenses - editorial - música - audiovisual - arquitectura - diseño - medios informáticos - radio - televisión - publicidad - patrimonio - educación e investigación cultural - fabricación de insumos.

Tabla 6: Análisis de las diferentes categorizaciones sobre las Industrias Creativas.

Elaboración propia a partir del informe Framework for Cultural Statistics de la UNESCO (2009), el modelo del Department of Culture, Media and Sports de Reino Unido (2001), la guía expuesta en la Conferencia de las Naciones Unidas sobre Comercio y Desarrollo, UNCTAD (2004), la teoría de círculos concéntricos de Thorsby (2007) y el Mapa de Industrias Creativas para Chile (2014).

\subsubsection{Categorización de las Industrias Creativas en Lima}

Para el presente estudio se elabora una propuesta de categorización del sector creativo según los datos encontrados, estableciendo siete áreas que permitan el reconocimiento de las Industrias Creativas en Lima 
Metropolitana. Se consideró pertinente dividir cada sector por actividades e infraestructuras para un posterior estudio de la clase creativa involucrada por su contribución a la economía local y a la tasa de empleos, por lo que se propone:

\section{ARTES ESCÉNICAS: $\quad$ ACTIVIDADES: artes circenses - baile, danza y ballet - música - ópera - performances urbanas - teatro. \\ INFRAESTRUCTURA: auditorios - circos - escuelas de danza - escuelas de música - escuelas de teatro - teatros.}
2. ARTES VISUALES: $\quad$ ACTIVIDADES: arte digital - artes plásticas - fotografía y arte digital - graffitis y murales - videoarte.
INFRAESTRUCTURA: escuelas de arte - escuelas de fotografía - galeria de arte - museos de arte - tiendas de materiales de arte.
3. DISEÑO: $\quad$ ACTIVIDADES: arquitectura - diseño de interiores - diseño de modas - diseño gráfico - diseño industrial - joyería. INFRAESTRUCTURA: escuelas de arquitectura y diseño - empresas de arquitectura y diseño - centros de impresión y diseño - centros de corte y confección - librerías de arquitectura y diseño - talleres de manufactura.

4. MEDIOS:
ACTIVIDADES: cine - internet - prensa - publicidad y marketing - radio - televisión.
INFRAESTRUCTURA: agencias de publicidad - canales de televisión - grupos de prensa - escuelas de comunicación -
estudios de radio y televisión - salas de cine.

\section{LITERATURA ACTIVIDADES: novela, poesía, cuento y ensayo - recitales - exposiciones literarias - talleres de escritura. INFRAESTRUCTURA: bibliotecas y salas de lectura - editoriales de libros y revistas - ferias de libro - librerias.}
6. PATRIMONIO ACTIVIDADES: artesanía tradicional - conservación de patrimonio - gastronomía - identidad e interculturalidad - CULTURAL: $\quad$ investigación y difusión cultural - turismo cultural. INFRAESTRUCTURA: archivos históricos - centros culturales - instituciones culturales - museos de historia y arqueología - patrimonio edificado - sitios arqueológicos.

\section{INNOVACIÓNY TECNOLOGÍA:}

Tabla 7: Propuesta de clasificación de las Industrias Creativas para Lima Metropolitana por actividades e infraestructuras. Elaboración propia.

\subsubsection{Mapeo como método de diagnóstico}

La presencia e impacto del sector creativo debe ser reconocido mediante un análisis espacial sobre el tejido urbano y económico del territorio, posibilitando la ubicación de las diferentes actividades económicas creativas en un mapa, "la intención principal del mapeo es la de poner en perspectiva el valor económico de las industrias creativas, particularmente en lugares donde no se sabe casi nada de ellas." (BOP Consulting, 2010: 9). Es decir, este método nos permitirá reconocer la localización de la clase creativa y el ámbito urbano con el que se relaciona y se ve influenciado, para la elaboración de un diagnóstico.

Una de las limitaciones para la elaboración del mapeo del presente estudio fue la poca disponibilidad de recursos de información sistemática y fiable. Actualmente el Ministerio de Cultura es la única institución nacional que tiene información abierta de carácter cultural y creativo, sin embargo esta no se encuentra actualizada y al tratarse de un sector en constante dinamismo, muchos de estos datos no se encuentran vigentes. Además esta información resulta insuficiente pues excluye a otros sectores creativos como diseño, medios e innovación. Por todo esto, el presente estudio se ha centrado en realizar un directorio de sectores creativos en Lima como aporte a la investigación, levantando, validando y unificando los datos encontrados para la producción de un directorio actualizado.

\subsection{Mapeo de las Industrias Creativas en Lima}

Para la toma de información se consideraron los 49 distritos que conforman Lima Metropolitana (LM). La base de datos generada se elaboró a partir de un análisis realizado para la presente investigación donde se llegó a muestrear 870 lugares donde se desarrolla algún tipo de actividad creativa y/o cultural. Las limitaciones en el acceso a datos para determinar la tasa de empleo y los ingresos económicos generados en estos lugares 
permiten únicamente desarrollar un mapa matriz que considere indicadores en base a la cantidad de actividades por distrito, donde se identifica posibles clústeres creativos.

\subsubsection{Directorio de sectores creativos en Lima}

Esta información considera únicamente distritos que disponen como mínimo una actividad creativa, para lo cual, el presente directorio está elaborado solo con 38 distritos de LM, de los cuales solo tres de ellos (Lima, Miraflores y San Isidro) abarcan el $44 \%$ del total de actividades creativas en la ciudad, siendo el distrito de Lima (ubicado en la zona central de LM) el que mayor cantidad de actividades engloba, representando casi un $20 \%$ del total. Esta cifra evidencia que no existe una aglomeración en un distrito específico, pero comparado con otros distritos existe una gran diferencia porcentual, esto debido a que Lima se caracteriza por ser una ciudad dispersa y segregada, donde la conectividad es un desafío para los planes urbanos.

\begin{tabular}{|c|c|c|c|c|c|c|c|c|c|c|}
\hline $\mathrm{N}^{\circ}$ & Distrito & $\begin{array}{c}\text { Artes } \\
\text { Escénicas }\end{array}$ & $\begin{array}{c}\text { Artes } \\
\text { Visuales }\end{array}$ & Diseño & Medios & Literatura & $\begin{array}{l}\text { Patrimonio } \\
\text { Cultural }\end{array}$ & $\begin{array}{l}\text { Innovación } \\
\text { y Tecnología }\end{array}$ & TOTAL & \\
\hline 1 & Ancón & 0 & 0 & 0 & 0 & 0 & 1 & 0 & 1 & \\
\hline 2 & Ate & 3 & 3 & 2 & 1 & 0 & 2 & 2 & 13 & 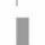 \\
\hline 3 & Barranco & 20 & 14 & 9 & 6 & 1 & 8 & 4 & 62 & \\
\hline 4 & Breña & 3 & 0 & 1 & 2 & 5 & 1 & 1 & 13 & 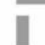 \\
\hline 5 & Callao & 1 & 0 & 0 & 0 & 0 & 3 & 1 & 5 & j \\
\hline 6 & Carabayllo & 4 & 0 & 0 & 2 & 0 & 0 & 0 & 6 & i \\
\hline 7 & Chorrillos & 5 & 1 & 1 & 6 & 0 & 1 & 1 & 15 & 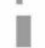 \\
\hline 8 & Cieneguilla & 0 & 1 & 0 & 1 & 1 & 0 & 0 & 3 & j \\
\hline 9 & Comas & 9 & 0 & 3 & 4 & 1 & 0 & 1 & 18 & च \\
\hline 10 & El Agustino & 3 & 0 & 0 & 1 & 1 & 0 & 0 & 5 & I \\
\hline 11 & Independencia & 4 & 1 & 3 & 2 & 4 & 0 & 3 & 17 & ๘ \\
\hline 12 & Jesús María & 9 & 3 & 3 & 7 & 11 & 13 & 2 & 48 & 口 \\
\hline 13 & La Molina & 2 & 5 & 2 & 5 & 4 & 4 & 5 & 27 & 口 \\
\hline 14 & La Perla & 1 & 0 & 0 & 0 & 0 & 0 & 0 & 1 & | \\
\hline 15 & La Victoria & 0 & 0 & 0 & 3 & 2 & 2 & 1 & 8 & I \\
\hline 16 & Lima & 34 & 17 & 7 & 30 & 22 & 47 & 16 & 173 & \\
\hline 17 & Lince & 1 & 1 & 1 & 3 & 3 & 2 & 1 & 12 & 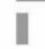 \\
\hline 18 & Los Olivos & 2 & 0 & 3 & 4 & 2 & 3 & 3 & 17 & ๘ \\
\hline 19 & Lurín & 0 & 0 & 0 & 0 & 0 & 1 & 0 & 1 & \\
\hline 20 & Magdalena del Mar & 5 & 1 & 1 & 0 & 7 & 5 & 0 & 19 & च \\
\hline 21 & Miraflores & 28 & 18 & 23 & 24 & 20 & 18 & 11 & 142 & 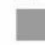 \\
\hline 22 & Pachacámac & 0 & 1 & 0 & 0 & 0 & 1 & 0 & 2 & 1 \\
\hline 23 & Pueblo Libre & 1 & 2 & 0 & 2 & 0 & 4 & 0 & 9 & I \\
\hline 24 & Puente Piedra & 1 & 0 & 1 & 1 & 0 & 0 & 1 & 4 & i \\
\hline 25 & Rímac & 2 & 0 & 0 & 2 & 3 & 6 & 6 & 19 & ] \\
\hline 26 & San Bartolo & 1 & 0 & 0 & 0 & 0 & 0 & 0 & 1 & \\
\hline 27 & San Borja & 3 & 2 & 1 & 5 & 4 & 2 & 2 & 19 & 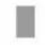 \\
\hline 28 & San Isidro & 8 & 5 & 9 & 16 & 7 & 8 & 18 & 71 & 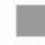 \\
\hline 29 & San Juan de Lurigancho & 6 & 1 & 3 & 1 & 1 & 2 & 5 & 19 & ] \\
\hline 30 & San Juan de Miraflores & 1 & 0 & 1 & 1 & 0 & 0 & 2 & 5 & I \\
\hline 31 & San Luis & 0 & 1 & 0 & 0 & 3 & 0 & 0 & 4 & 1 \\
\hline 32 & San Martín de Porres & 2 & 2 & 0 & 0 & 0 & 1 & 0 & 5 & I \\
\hline 33 & San Miguel & 1 & 5 & 3 & 4 & 5 & 4 & 10 & 32 & 口 \\
\hline 34 & Surquillo & 1 & 1 & 0 & 2 & 1 & 0 & 4 & 9 & I \\
\hline 35 & Santa Anita & 0 & 0 & 0 & 1 & 0 & 0 & 2 & 3 & \\
\hline 36 & Santiago de Surco & 1 & 1 & 6 & 5 & 12 & 6 & 8 & 39 & 口 \\
\hline 37 & Villa El Salvador & 11 & 0 & 0 & 2 & 0 & 1 & 3 & 17 & 【 \\
\hline \multirow[t]{2}{*}{38} & Villa María del Triunfo & 3 & 2 & 0 & 1 & 0 & 0 & 0 & 6 & I \\
\hline & & 176 & 88 & 83 & 144 & 120 & 146 & 113 & 870 & \\
\hline
\end{tabular}

Tabla 8: Clasificación de las actividades creativas en los diferentes distritos de Lima Metropolitana. 


\subsubsection{Análisis y diagnóstico}

Del total de 49 distritos que conforman LM, se observa que solo 08 distritos de Lima-Centro (Barranco, Jesús María, La Molina, Lima, Miraflores, San Isidro, San Miguel y Santiago de Surco) concentran una cantidad significativa de ICC, lo cual contrasta con el escaso número de industrias identificadas en la periferia. La localización de las empresas creativas en los centros consolidados de la ciudad, evidencia una correspondencia entre la concentración económica creativa y las condiciones urbanas de una estructura territorial metropolitana aún en proceso de descentralización.

El distrito con mayor participación en actividades creativas es Lima que llega a tener un total de 173 actividades cuyo sector predominante es el de Patrimonio Cultural, esto se debe a que dentro del distrito se encuentra el Centro Histórico que abarca una red de infraestructuras culturales, patrimoniales e históricas.

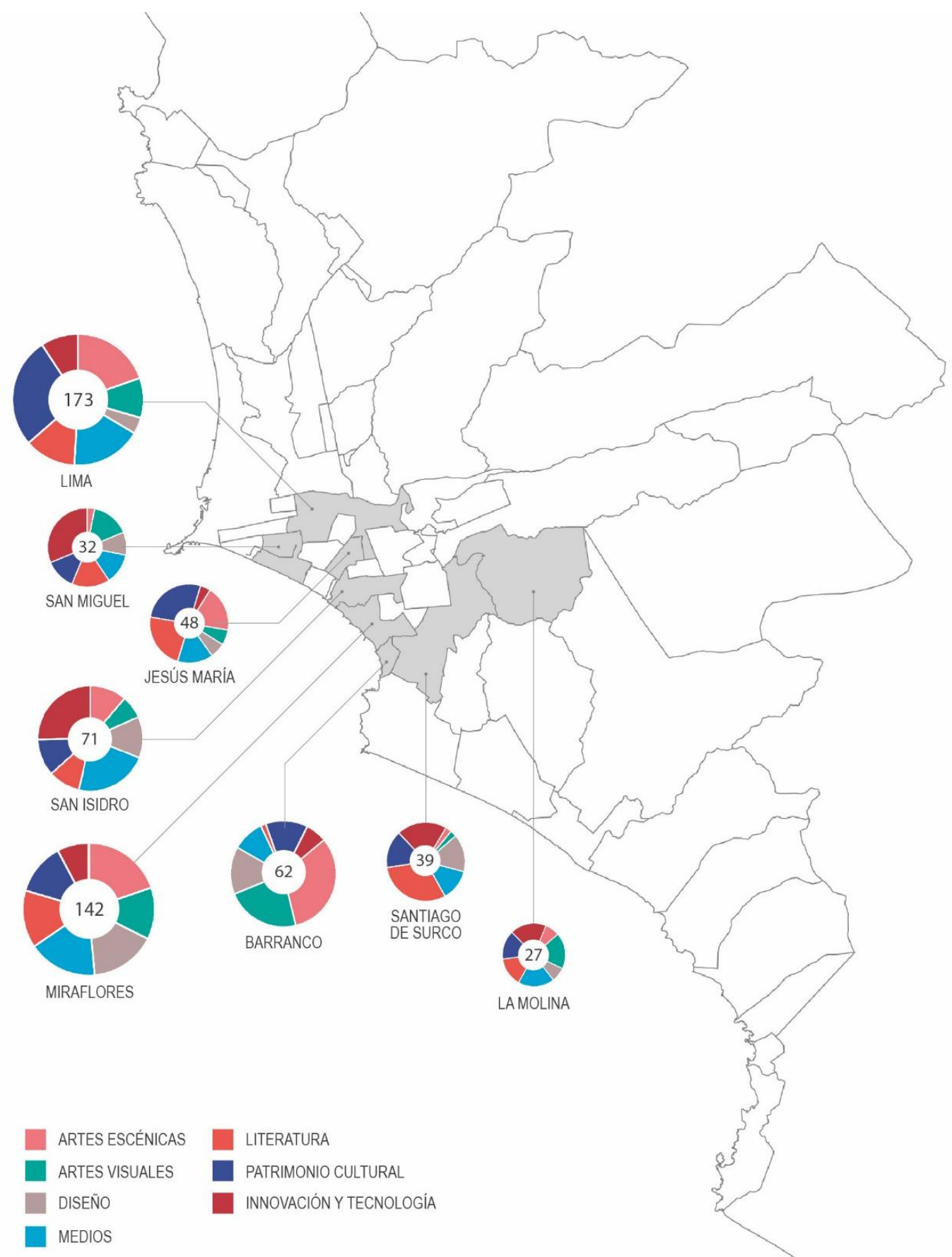

Figura 1: Análisis espacial de las principales Industrias Creativas en Lima Metropolitana. 
En segundo, tercer y cuarto orden se encuentran los distritos de Miraflores, San Isidro y Barranco respectivamente con 142, 71 y 62 actividades. A diferencia de Lima, estos distritos se asientan sobre un tejido urbano más consolidado y con mejores ingresos, los cuales responden a una dotación de mejores infraestructuras y calidad de servicios para sus ocupantes, quienes podrían ser considerados la clase creativa joven de la ciudad, abarcando principalmente sectores creativos como Medios, Innovación y Tecnología, y Artes Visuales. Cabe resaltar que estos distritos comparten límites físicos, lo cual es favorable para una propuesta integral de desarrollo como fortalecimiento de las Industrias Creativas en Lima.

Asimismo, la presente investigación desglosa la base de datos creada en función de las categorías consideradas para este análisis identificando la aglomeración espacial de cada sector, con el objetivo de contribuir a siguientes aproximaciones en la delimitación de más clústeres creativos que apunte a un estudio más profundo hacia la configuración de una estructura urbana policéntrica.

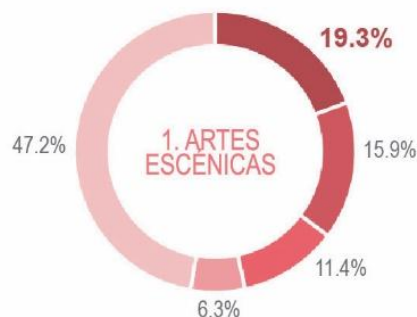

- LIMA mIRAFLORES BARRANCO - VILLAEL SALVADOR OTROS

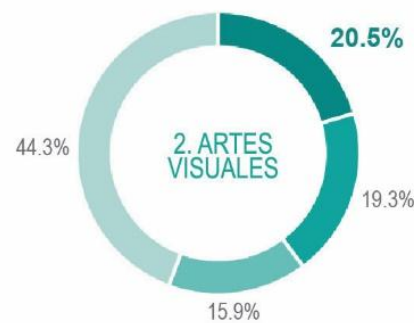

- MIRAFLORES $\square$ LIMA $\square$ BARRANCO OTROS

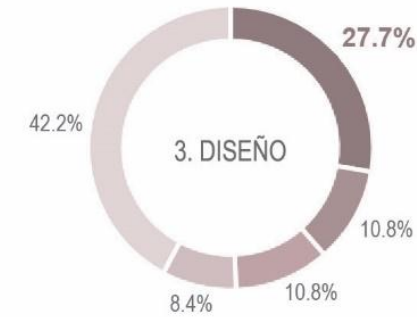

m MIRAFLORES BARRANCO $\square$ SAN ISIDRO - LIMA OTROS

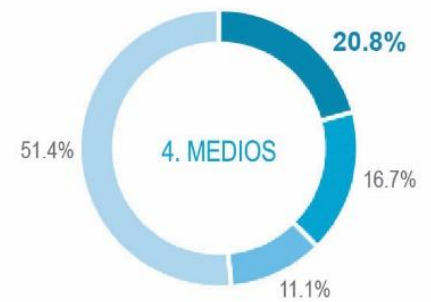

- LIMA MIRAFLORES OTROS

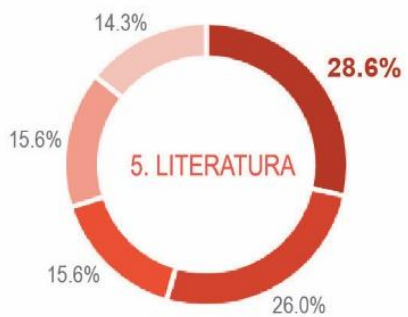

- LIMA MIRAFLORES - SANTIAGO DE SURCO - JESUS MARIA
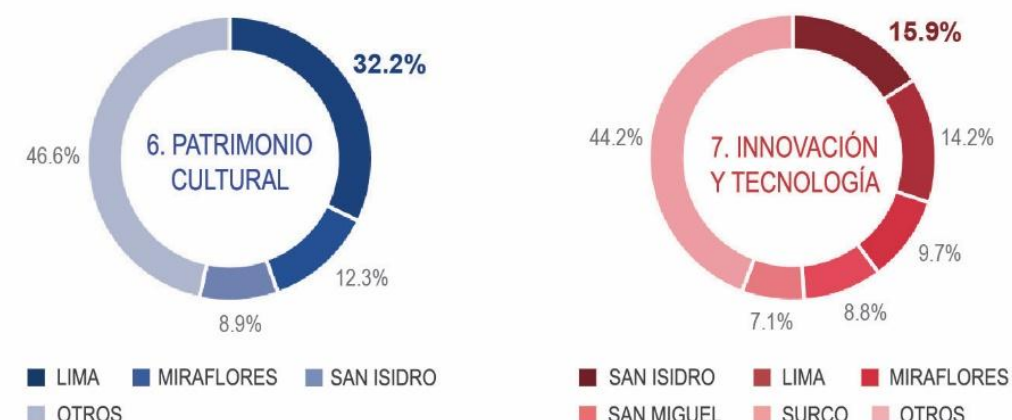

Figura 2: Desglose de los diferentes sectores creativos por distritos.

Elaboración propia.

De este análisis, se concluye que el sector de las Artes Escénicas se concentra principalmente en los distritos de Lima (19.3\%), Miraflores (15.9\%), Barranco (11.4\%) y Villa El Salvador (6.3\%). Resalta la presencia de un distrito periférico del sector de Lima-Norte, aunque cabe resaltar que las empresas creativas identificadas corresponden a colectivos artísticos de arte callejero con equipamiento insuficiente y en mal estado.

El sector de las Artes Visuales se aglomera en los distritos de Miraflores (20.5\%), Lima (19.3\%) y Barranco (15.9\%), donde se observa un número significativo de museos, galerías y escuelas de arte visual. Las 
industrias creativas del sector de Diseño se concentran en Lima-Centro, donde destacan centros de formación como escuelas de diseño y empresas de difusión como galerías y tiendas de diseño.

En el sector de Medios, las empresas que sobresalen son las agencias publicitarias y las que pertenecen a medios de comunicación tradicionales como radio y televisión.

Para el sector de Literatura podemos inferir que no existe un grado de aglomeración tan notorio como en los otros sectores analizados. Sin embargo, es necesario un análisis más profundo para diferenciar las industrias de formación, producción y comercialización.

En el sector Patrimonio cultural se observa que el porcentaje mayor de empresas culturales se aglomeran en el distrito de Lima (32\%), esto debido a la herencia cultural del mismo.

Finalmente, las empresas creativas relacionadas al sector de Innovación y Tecnología, a pesar de ser una industria incipiente, se encuentran localizadas en diversos distritos. Resaltan aquellos donde se encuentran universidades, tal es el caso de la Pontificia Universidad Católica del Perú en San Miguel (8.8\%), que alberga diversas iniciativas de industrias creativas en este sector.

Este diagnóstico permite reconocer cómo es la distribución de cada sector creativo por distritos dominantes que en su mayoría se encuentran en la parte central de Lima Metropolitana, pudiendo identificar físicamente los diferentes grados de clústeres en formación dentro de un contexto global delimitado.

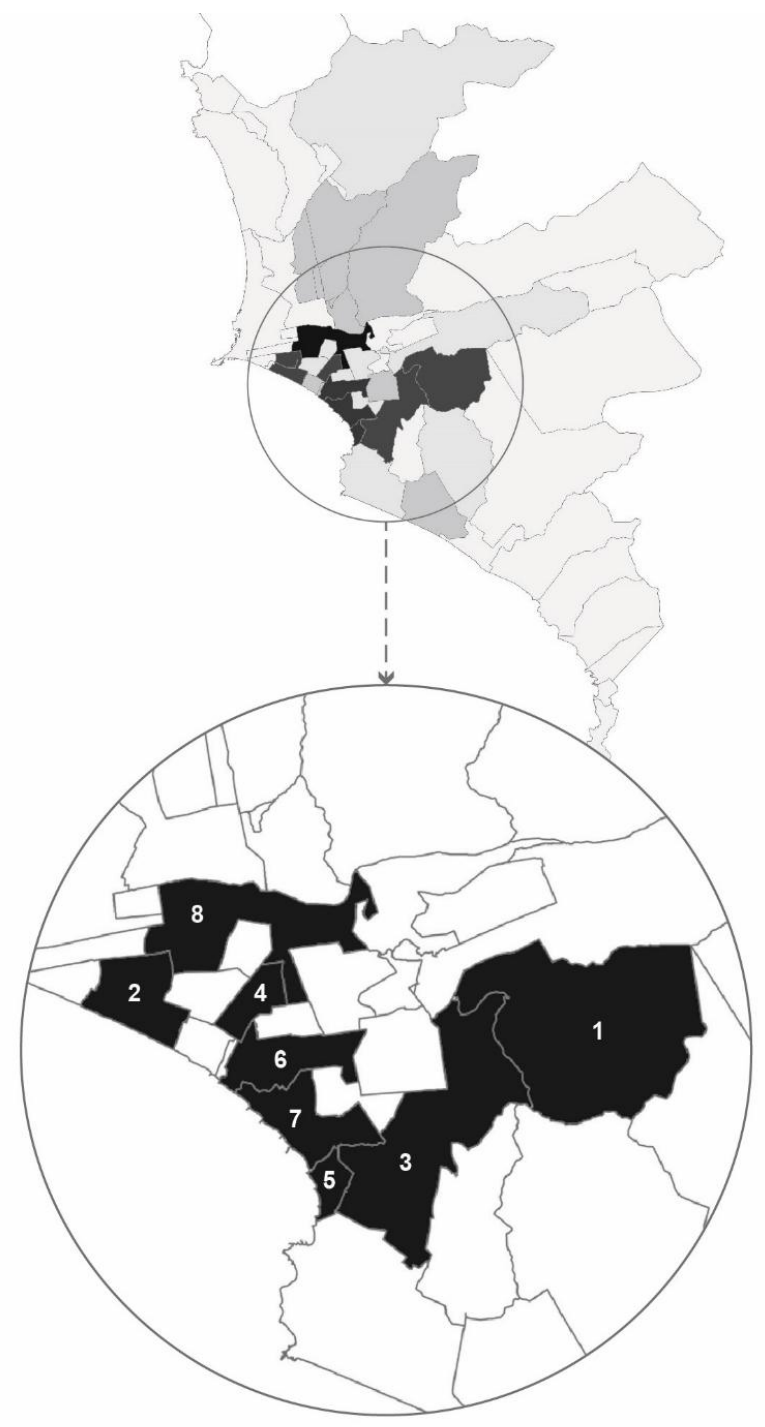

\begin{tabular}{|c|c|c|c|}
\hline DISTRITO & ACTIV. & \multicolumn{2}{|c|}{ TOTAL } \\
\hline La Perla & 1 & \multirow{13}{*}{40} & \multirow{13}{*}{$4.60 \%$} \\
\hline San Bartolo & 1 & & \\
\hline Ancón & 1 & & \\
\hline Lurín & 1 & & \\
\hline Pachacámac & 2 & & \\
\hline Cieneguilla & 3 & & \\
\hline Santa Anita & 3 & & \\
\hline San Luis & 4 & & \\
\hline Puente Piedra & 4 & & \\
\hline El Agustino & 5 & & \\
\hline San Martin de Porres & 5 & & \\
\hline Callao & 5 & & \\
\hline San Juan de Miraflores & 5 & & \\
\hline Villa Maria del Triunfo & 6 & \multirow{9}{*}{91} & \multirow{9}{*}{$10.46 \%$} \\
\hline Carabayllo & 6 & & \\
\hline La Victoria & 8 & & \\
\hline Pueblo Libre & 9 & & \\
\hline Surquillo & 9 & & \\
\hline Lince & 12 & & \\
\hline Breña & 13 & & \\
\hline Ate & 13 & & \\
\hline Chorrillos & 15 & & \\
\hline Independencia & 17 & \multirow{8}{*}{145} & \multirow{8}{*}{$16.67 \%$} \\
\hline Villa EI Salvador & 17 & & \\
\hline Los Olivos & 17 & & \\
\hline Comas & 18 & & \\
\hline Magdalena del Mar & 19 & & \\
\hline San Borja & 19 & & \\
\hline San Juan de Lurigancho & 19 & & \\
\hline Rímac & 19 & & \\
\hline La Molina & 27 & \multirow{4}{*}{146} & \multirow{4}{*}{$16.78 \%$} \\
\hline San Miguel & 32 & & \\
\hline Santiago de Surco & 39 & & \\
\hline Jesús María & 48 & & \\
\hline Barranco & 62 & \multirow{3}{*}{275} & \multirow{3}{*}{$31.61 \%$} \\
\hline San Isidro & 71 & & \\
\hline Miraflores & 142 & & \\
\hline \multirow[t]{2}{*}{ Lima } & 173 & 173 & $19.89 \%$ \\
\hline & & 870 & $100.00 \%$ \\
\hline
\end{tabular}

Figura 3: Delimitación espacial de las principales Industrias Creativas en la zona central de Lima Metropolitana. Elaboración propia. 

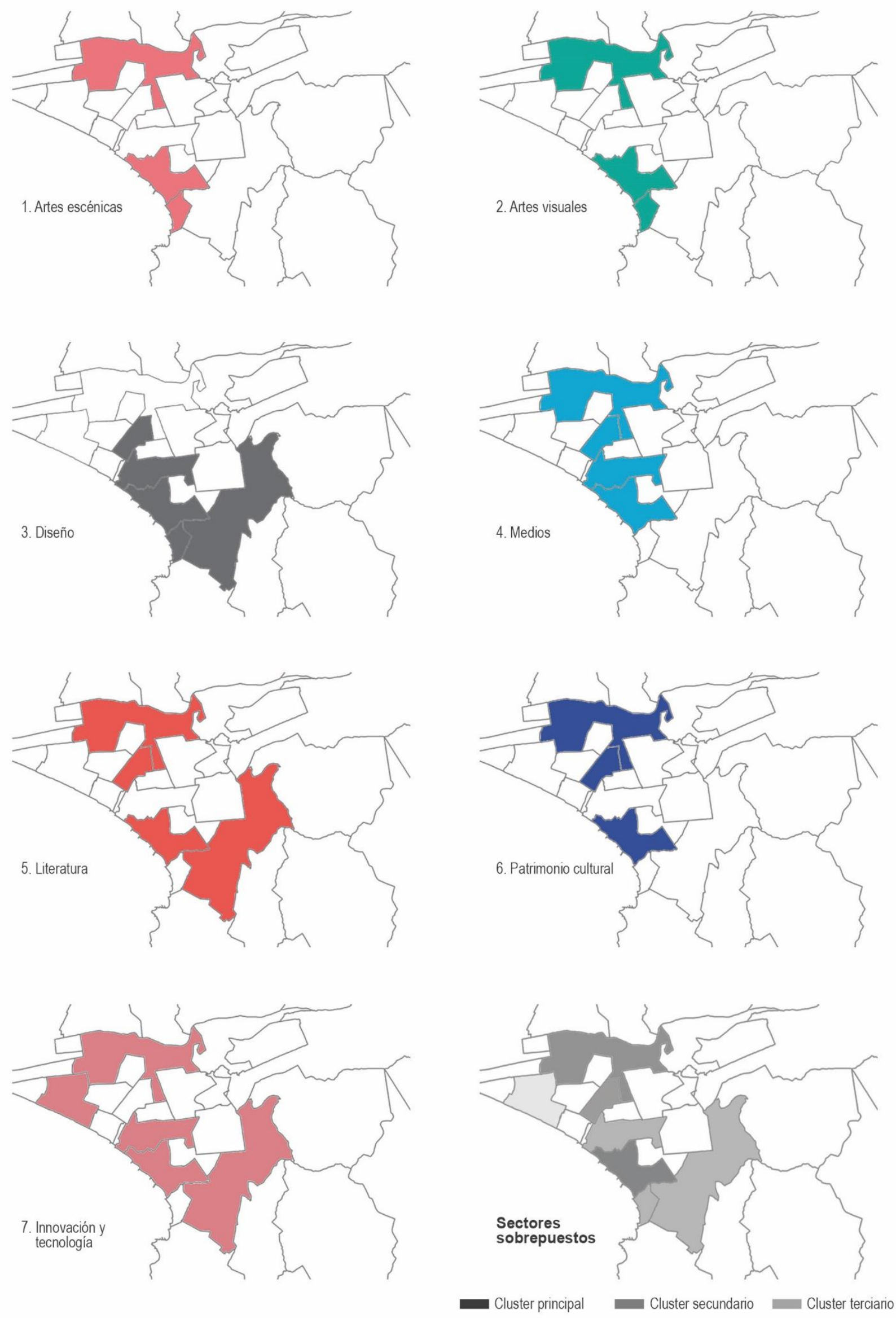

Figura 4: Evaluación y reconocimiento de posibles clústeres creativos en la zona central de Lima Metropolitana. Elaboración propia. 
La Figura 4 muestra la disposición física que ocupan los diferentes sectores creativos sobre la zona central de Lima Metropolitana de acuerdo al número de actividades encontradas por distrito. Al sobreponer las diferentes capas, se puede inferir que los distritos de Lima y Miraflores poseen la mayor aglomeración de diversos sectores entrelazados, considerándolos así como clústeres principales. Este resultado no responde a la cantidad total de actividades por distrito, pues el directorio elaborado solo cuantifica de forma ponderada la data recogida. La técnica de mapeo muestra las zonas del territorio que poseen la mayor aglomeración integral de sectores creativos para clasificar así los diferentes clústeres con alto potencial en ICC según su concentración espacial. Igualmente se observa que el distrito de Jesús María (contiguo a Lima) aglomera también gran parte de los sectores creativos, por lo que podría complementarse con el clúster de Lima, consiguiendo beneficios económicos y de desarrollo.

Como clústeres secundarios y terciarios se observan los distritos de San Isidro, Barranco, Santiago de Surco y finalmente San Miguel, quienes a diferencia de Lima y Miraflores, resaltan por tener sectores muy específicos y propios a su condición de desarrollo, lo cual los hace menos competitivos en el contexto global de las ICC, ya que no destaca una aglomeración espacial en sus territorios. Por otro lado y de forma positiva, estos distritos poseen una consolidación de sectores creativos exclusivos (ver Figura 2), como es el caso de San Isidro que destaca en el sector de Innovación y Tecnología, donde se viene trabajando desde el gobierno local con programas como el "Lab San Isidro" que es el primer laboratorio municipal de innovación en el Perú y también es epicentro de programas de startups. De la misma manera, Barranco posee una gran consolidación del sector de Artes y Diseño, ya que vienen desarrollando proyectos como el: Perú Arte Contemporáneo (PARC) y eventos como el Barranco Open Studios y la Noche en Blanco donde se abre el distrito a visitantes con recorridos artísticos.

\subsection{Lineamientos y desafíos de las Industrias Creativas en el contexto económico-urbano}

La diversidad de sectores y actividades de las ICC permite resaltar la multiculturalidad e interdisciplinariedad de la ciudad, lo cual es beneficioso para su contexto socio-económico, pues permite fomentar y preservar los diferentes valores, tradiciones y costumbres de nuestra cultura. Por tal motivo, el Ministerio de Cultura debe liderar estrategias junto con diferentes agentes privados y públicos para promover el desarrollo de las ICC, logrando así una inclusión social y económica, consolidando a la clase creativa. Por otro lado, a lo largo del estudio se han encontrado limitaciones en cuanto al acceso a la información y existencia de datos que faciliten el desarrollo de la propuesta, por lo cual es necesario tomar acciones para la implementación de sistemas de estadísticas y Cuentas Satélites de Cultura para lograr medir, comprender y analizar las diferentes economías creativas.

A partir de un análisis más profundo de las lógicas de especialización de las actividades creativas dominantes en cada distrito, los gobiernos locales deben establecer políticas para la promoción de clústeres creativos localizados para favorecer la complementariedad entre empresas del mismo sector que generen ventajas competitivas derivadas de las dinámicas de proximidad espacial. Asimismo se deberán analizar las conexiones globales entre los distintos sectores para configurar redes de interacción entre clústeres y evitar estructuras cerradas y dependencias productivas, impidiendo la segregación socio-espacial y garantizando la protección del patrimonio cultural.

\section{CONCLUSIONES}

La economía peruana está creciendo exponencialmente posicionándose sobre las demás economías latinoamericanas, siendo el momento para impulsar la inversión pública y privada en los sectores culturales, específicamente en las ICC que constituyen alrededor del 7\% de empleo total global en Latinoamérica (EY, 2015). Lima necesita aplicar este nuevo modelo de crecimiento, generando nuevos puestos de trabajo y resolviendo sus necesidades con soluciones alternativas más eficientes, implementado mecanismos de medición constante para promover el mejoramiento de la infraestructura cultural, fomentando la inclusión social y la mejora laboral a través del emprendimiento e innovación.

El fomento de las Industrias Creativas permitirá establecer nuevos criterios para la idealización de planes y proyectos de desarrollo urbano, considerando trabajar en un modelo de territorio inteligente que opere de manera conjunta entre los sectores económicos y sociales consolidados y los emergentes junto a las nuevas tecnologías. Este estudio tentativo parte de la iniciativa de aportar con el futuro y mejora de la ciudad encaminándola hacia un desarrollo sostenible. 


\section{BIBLIOGRAFÍA}

ADORNO, T. y HORKHEIMER, M. (1944) La Dialéctica del Iluminismo. Mimeo.

ALONSO, G. (2009). Creatividad, cultura y desarrollo económico. Pensamiento Iberoamericano, 4, 151-165.

BOIX, R., y LAZZERETTI, L. (2012). Las industrias creativas en España: una panorámica. Investigaciones Regionales. 22, 181-206.

BOP CONSULTING (2010). Guía práctica para mapear las industrias creativas. Londres: British Council/ ODAL.

CALDERERO, A., PÉREZ, J., y UGALDE, I. Territorio inteligente y espacio de economía creativa: una primera aproximación conceptual y práctica de investigación. XVI Congreso de Estudios Vascos: Garapen Iraunkorra-IT, Donostia, julio-setiembre.

CASANI, F. et al. (2010). Sectores de la nueva economía 20+20. Industrias de la creatividad. EOI: Escuela de Organización Industrial.

CONSEJO NACIONAL DE LA CULTURA Y LAS ARTES (2014). Mapeo de las Industrias Creativas en Chile. Caracterización y dimensionamiento. Santiago de Chile: Publicaciones Cultura.

CONVENIO ANDRÉS BELLO (2009). Cuentas Satélites de Cultura. Manual metodológico para su implementación en Latinoamérica. Colección cultura y desarrollo. Bogotá: Convenio Andrés Bello.

DUQUE, I. (2015). La cultura como estrategia de transformación y promoción urbana en Bogotá y Medellín. Revista de geografía Norte Grande, (61), 25-43.

ESPÍNDOLA, E., y CEPAL (2014). Cultura y desarrollo económico en Iberoamérica. Madrid: OEI.

EY (2015). Tiempos de cultura. El primer mapa mundial de las industrias culturales y creativas.

FMI, Fondo Monetario Internacional (2016). Perspectivas de la economía mundial.

FLORIDA, R. (2002). The rise of the creative class: and how it's transforming work, leisure, community and everyday life. New York: Basic Books.

(2010). La clase creativa. Madrid: Paidós.

FONSECA, A. (2008). Economía creativa como estrategia de desarrollo: una visión de los países en desarrollo. Sao Paulo: Itaú Cultural.

GUZMÁN, E., MEDINA, C. y AGUILAR, Q. (2005). La dinámica económica de la cultura en Venezuela y su contribución en el PIB. Unidad Editorial, CAB.

HALL, P. (2008). El contexto social, espacial y cultural de la innovación. Entornos, clusters y ciudades creativas. Telos, 77, 71-76.

HERRERA, E., BONILLA, H. y MOLINA, L. (2013). Ciudades creativas: ¿paradigma económico para el diseño y la planeación urbana?. Bitácora Urbano Territorial, 1(22).

HOWKINS, J. (2002). The creative economy: how people make money from ideas. London: The Penguin Press.

INEI, Instituto Nacional de Estadística e Informática (2015a). Informe de producción y empleo informal en el Perú

INEI, Instituto Nacional de Estadística e Informática (2015b). Población económicamente activa ocupada, según ramas de actividad y ámbito geográfico, $2009-2015$.

INEI, Instituto Nacional de Estadística e Informática (2015c). Total Actividades Económicas, por País 2007 2015.

INEI, Instituto Nacional de Estadística e Informática (2015d). PBI de los Departamentos, según actividades económicas, Lima 2007 - 2015.

INEI, Instituto Nacional de Estadística e Informática (2016). Comportamiento de la Economia Peruana en el Tercer Trimestre del 2016.

LANDRY, C. (2012). The creative city: A toolkit for urban innovators. Londres: Earthscan.

LANDRY, C., y BIANCHINI, F. (1995). The creative city. Londres: Demos.

LIMA CÓMO VAMOS (2015). Evaluando la Gestión en Lima - Sexto informe de resultados sobre calidad de vida.

MANITO, F. (2007). Cultura y estrategia de ciudad. La centralidad del sector cultural en la agenda local. Barcelona: Centro Iberoamericano de Desarrollo Estratégico Urbano.

(2009). Ciudades creativas Vol. 1: Cultura, territorio, economía y ciudad. Madrid: Ediciones Bellatierra.

(2010). Ciudades creativas Vol. 2: Creatividad, innovación, cultura y agenda local. Madrid: Ediciones Bellatierra.

(2011). Ciudades creativas Vol. 3: Economía creativa, desarrollo urbano y políticas públicas. Madrid: Ediciones Bellatierra.

MINISTERIO DE TRABAJO Y PROMOCIÓN DEL EMPLEO (2015). Informe Anual del Empleo en el Perú 2014. 
PIEDRAS, E. (2004). ¿Cuánto vale la cultura? Contribución económica de las industrias protegidas por el derecho de autor en México. México: Conaculta.

SALINAS, L. (2013). Gentrificación en la ciudad latinoamericana. El caso de Buenos Aires y Ciudad de México. GeoGraphos: Revista Digital para Estudiantes de Geografía y Ciencias Sociales, 4(44), 281-304.

RESTREPO, F. B., y MÁRQUEZ, I. D. (2013). La economía naranja: una oportunidad infinita. Banco Interamericano de Desarrollo.

UNESCO (2009). Framework For Cultural Statistics. UNESCO Institute for Statistics (UIS). (2010). Políticas para la creatividad. Guía para el desarrollo de las industrias culturales y creativas. (2014). Indicadores UNESCO de cultura para el desarrollo. Resumen analítico de Colombia.

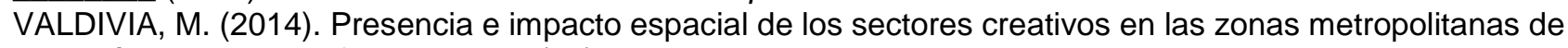
México. Estudios fronterizos, 15(30), 215-259.

VÁSQUEZ, D. (2009). El debate de las industrias culturales en América Latina y la Unión Europea. Estudios sobre las culturas contemporáneas, (30), 61-84.

YUDICE, G. (2008). Modelos de desarrollo cultural urbano: ¿gentrificación o urbanismo social?. Alteridades, 18(36), 47-61.

ZALLO, R. (2009). Industrias culturales y ciudades creativas. Recuperado de: www.ramonzallo.com/wpcontent/uploads/2012/02/kreanta-publicacion.pdf

ZURBANO, M. (2005). Las regiones como sujetos de la economía global. Euskadi en la gobernanza multidimensional. Ekonomiaz, 1(58), 196-231. 